Article

\title{
The Effect of Increasing Inclusion Levels of a Fucoidan-Rich Extract Derived from Ascophyllum nodosum on Growth Performance and Aspects of Intestinal Health of Pigs Post-Weaning
}

\author{
Ruth Rattigan ${ }^{1}$, Torres Sweeney ${ }^{2}(\mathbb{D})$, Stafford Vigors ${ }^{1}$, Kevin Thornton ${ }^{2}$, Gaurav Rajauria ${ }^{1}$ (D) \\ and John V O'Doherty ${ }^{1, *(D)}$ \\ 1 School of Agriculture and Food Science, University College Dublin, Belfield, 4 Dublin, Ireland; \\ ruth.rattigan@ucdconnect.ie (R.R.); staffordvigors1@ucd.ie (S.V.); gaurav.rajauria@ucd.ie (G.R.) \\ 2 School of Veterinary Medicine, University College Dublin, Belfield, 4 Dublin, Ireland; \\ torres.sweeney@ucd.ie (T.S.); kevin.thornton@ucd.ie (K.T.) \\ * Correspondence: john.vodoherty@ucd.ie; Tel.: +35-317-167-128
}

Received: 1 November 2019; Accepted: 27 November 2019; Published: 30 November 2019

\begin{abstract}
This study examines the effects of increasing dietary inclusion levels of fucoidan, from a $44 \%$ fucoidan extract on the growth performance and intestinal health of pigs post-weaning (PW). Seventy-two newly weaned pigs (8.4 kg (SD 1.06)) were assigned to: (T1) basal diet (BD); (T2) BD + 125 ppm fucoidan; (T3) BD +250 ppm fucoidan (8 pens/treatment). The appropriate quantity of a $44 \%$ fucoidan extract was included to achieve these inclusion levels. Faecal scores were recorded daily. On d15 PW, samples were collected from the intestinal tract from 1 pig/pen from the BD and BD +250 ppm fucoidan groups. Pigs supplemented with $250 \mathrm{ppm}$ fucoidan had improved faecal scores and increased concentrations of total volatile fatty acids and propionate in the colon $(p$ $<0.05$ ). The fucoidan-rich extract reduced the expression of CLDN5 (duodenum), SCL5A1/SGLT1 and SI (jejunum) and TJP1, FABP2, and SLC5A1 (ileum) $(p<0.05)$. The extract reduced the relative abundance of Prevotella and Lachnospiraceae $(p<0.05)$ and increased the abundance of Helicobacter $(p<0.01)$ in the caecum. However, no negative impact on growth performance or small intestinal morphology was observed. Thus, the inclusion of $250 \mathrm{ppm}$ fucoidan improves faecal consistency without affecting growth performance and therefore warrants further investigation as a supplement for the prevention of PW diarrhoea under more challenging commercial conditions.
\end{abstract}

Keywords: pigs; post-weaning diarrhoea; fucoidan; microbiota; growth performance

\section{Introduction}

On modern commercial pig farms, weaning is an abrupt process, resulting in severe stress and a transient reduction in feed intake and growth rates [1-3]. This stress increases the piglet's susceptibility to gastrointestinal disturbance, which is characterised by inflammation, increased epithelial permeability, and the maldigestion and malabsorption of nutrients. The proliferation of pathogenic bacteria in particular enterotoxigenic Escherichia coli $[3,4]$ often leads to post-weaning diarrhoea. Traditionally, antibiotic growth promoters (AGP) and pharmacological doses of zinc oxide $(\mathrm{ZnO})$ have been used to supplement the diets of newly weaned pigs to enhance growth and prevent the proliferation of pathogenic bacteria. However, owing to the role of AGP in the rise of antimicrobial resistance, the EU banned the use of AGPs in 2006 (EC Regulation no. 1831/2003). Now concerns surrounding the relationship between $\mathrm{ZnO}$ and antimicrobial resistance and the risk of environmental accumulation have led to a decision to ban pharmacological doses of $\mathrm{ZnO}$ in the EU from 2022 
(Commission Implementing Decision of 26.6.2017, C (2017) 4529 Final). In addition, the EU will also implement further restrictions on the use of antibiotics for the treatment of groups of animals from 2022 [5]. Thus, identifying natural alternatives will be important if we are to maintain future animal growth and health during the turbulent post-weaning period.

Brown seaweeds such as Ascophyllum nodosum are a valuable source of bioactive polysaccharides, including laminarin, alginates, mannitol, phlorotannins and fucoidans [6]. Fucoidans are sulphated, fucose rich polymers present in the algal cell wall [7]. They are chemically complex polysaccharides with varying compositions and molecular weights, but typically comprise a backbone of $(1 \rightarrow 3)$-linked $\alpha$-l-fucopyranosyl or of alternating $(1 \rightarrow 3)$ - and $(1 \rightarrow 4)$-linked $\alpha$-l-fucopyranosyl residues [8]. Identified biological activities include antimicrobial, immunomodulatory, antioxidant and antiviral effects [9-11], and as fucoidan is a non-digestible polysaccharide, it may also have prebiotic effects [6]. In pigs, fucoidan increased lactobacilli in the caecal digesta [12], colonic digesta [13] and faeces [14,15] and caecal and colonic butyrate concentrations [12]. The gastrointestinal microbiota contributes to host health and growth through the fermentation of carbohydrates, production of vitamins, healthy maintenance of the intestinal epithelium, immune and neural system development in neonates and protection from opportunistic pathogenic bacteria [16,17]. Thus, dietary supplementation with fucoidan may beneficially influence the composition of the intestinal microbiota of the newly weaned pig and thus, prevent the overgrowth of pathogenic bacteria and the onset of post-weaning diarrhoea.

However, the polysaccharide content and composition of seaweeds vary with season, the region of harvest, macroalgal species and extraction procedure $[18,19]$. Ascophyllum nodosum has been reported to contain $4 \%-11 \%$ fucoidan, $24 \%-28 \%$ alginate, $5 \%-11 \%$ mannitol and $1 \%-10 \%$ laminarin [6]. While research is under way to develop new innovative extraction methodologies to achieve high yields of purified polysaccharides, the currently used traditional extraction and purification processes are costly and inefficient in terms of energy usage and time (as reviewed by [20]). Thus, the first objective of this study is to determine the effect of increasing fucoidan inclusion levels from an extract containing $44 \%$ fucoidan from Ascophyllum nodosum on the faecal scores and large intestinal microbiota of weaned pigs. It is hypothesised that the optimum inclusion level of fucoidan will enhance the large intestinal microbiota, thereby reducing the incidence of post-weaning diarrhoea. Previously increasing dietary inclusion of an Ascophyllum nodosum extract led to a linear reduction in the daily gains of grower finisher pigs associated with reduced diet digestibility [21]. As the digestive system of the pig is not fully developed at weaning, higher inclusion levels may negatively impact pig growth performance and small intestinal functionality due to the increased levels of non-digestible fibre present (fucoidan $(44 \%)$ and alginates $(13.5 \%)$ ). Thus, a further objective of this study is to identify the effects of the fucoidan-rich extract on growth performance and parameters related to small intestinal health including morphology, the expression of genes involved in nutrient digestion and absorption, inflammation, mucus production, pathogen recognition and tight junctions.

\section{Results}

\subsection{Performance and Faecal Scores}

This study investigated the effects of increasing dietary inclusion levels of a fucoidan-rich extract containing $44 \%$ fucoidan, $2.59 \%$ laminarin, $13.5 \%$ alginates, $4.38 \%$ mannitol, $3.48 \%$ phlorotannins and $31.95 \%$ ash on pig growth performance and faecal scores in the first 14 days post-weaning. The effects on average daily gain (ADG), average daily feed intake (ADFI), gain to feed ratio (G:F) and faecal score (FS) are presented in Table 1. There was no difference in ADG, ADFI or G:F during the 14-day experimental period. For the duration of the experiment, pigs supplemented with $250 \mathrm{ppm}$ fucoidan had lower faecal scores compared with the basal group $(p<0.05)$. 
Table 1. Effect of increasing fucoidan inclusion level on pig growth performance and faecal consistency (least square means with their standard errors).

\begin{tabular}{|c|c|c|c|c|c|c|c|c|c|c|}
\hline & \multicolumn{3}{|c|}{$\begin{array}{l}\text { Fucoidan Inclusion Level } \\
\text { (PPM) * }\end{array}$} & \multirow[t]{2}{*}{ SEM } & \multicolumn{2}{|c|}{ Time (day) } & \multirow[t]{2}{*}{ SEM } & \multicolumn{3}{|c|}{$p$-Values } \\
\hline & 0 & 125 & 250 & & 7 & 14 & & Treatm & t Time & Treatment $\times$ Time \\
\hline ADFI (kg) & 0.319 & 0.308 & 0.340 & 0.011 & 0.209 & 0.435 & 0.009 & 0.104 & $<0.001$ & 0.378 \\
\hline $\mathrm{G}: \mathrm{F}$ & 0.467 & 0.403 & 0.517 & 0.060 & 0.391 & 0.533 & 0.049 & 0.430 & 0.042 & 0.846 \\
\hline
\end{tabular}

ADG, average daily gain; ADFI, average daily feed intake; G:F, gain to feed ratio; FS, faecal score; $d$, days; a,b Mean values within a row with unlike superscript letters were significantly different $(p<0.05)$. ${ }^{*}$ A total of eight replicates were used per treatment group (replicate = pen, 3 pigs/pen).

\subsection{Small Intestinal Morphology}

Villus height and crypt depth were measured in the three segments of the small intestine to evaluate the effect of fucoidan supplementation on intestinal morphology, as described in the materials and methods. Supplementation with $250 \mathrm{ppm}$ fucoidan had no effect on small intestinal morphology in either the duodenum, jejunum or ileum (data presented in Table 2).

Table 2. Effect of $250 \mathrm{ppm}$ fucoidan on villus height and crypt depth in the small intestine (least square means with their standard errors).

\begin{tabular}{|c|c|c|c|c|}
\hline & Basal * & Fucoidan 250 ppm * & SEM & $p$-Value \\
\hline \multicolumn{5}{|c|}{ Duodenum } \\
\hline $\mathrm{VH} \mu \mathrm{m}$ & 219.32 & 228.61 & 49.58 & 0.696 \\
\hline $\mathrm{CD} \mu \mathrm{m}$ & 112.88 & 125.20 & 21.14 & 0.234 \\
\hline VH:CD & 1.95 & 1.86 & 0.43 & 0.660 \\
\hline \multicolumn{5}{|c|}{ Jejunum } \\
\hline $\mathrm{VH} \mu \mathrm{m}$ & 212.42 & 231.87 & 48.15 & 0.404 \\
\hline $\mathrm{CD} \mu \mathrm{m}$ & 135.27 & 149.62 & 32.71 & 0.366 \\
\hline VH:CD & 1.59 & 1.60 & 0.36 & 0.928 \\
\hline \multicolumn{5}{|c|}{ Ileum } \\
\hline $\mathrm{VH} \mu \mathrm{m}$ & 242.43 & 249.74 & 49.90 & 0.760 \\
\hline $\mathrm{CD} \mu \mathrm{m}$ & 125.68 & 121.59 & 26.77 & 0.750 \\
\hline VH:CD & 1.98 & 2.11 & 0.49 & 0.602 \\
\hline
\end{tabular}

$\mathrm{VH}$, villus height; $\mathrm{CD}$, crypt depth; $\mathrm{VH}: \mathrm{CD}$, villus height to crypt depth ratio; * a total of 8 replicates were used per treatment group.

\subsection{Large Intestinal Microbiota and Volatile Fatty Acids (VFA)}

The effect of $250 \mathrm{ppm}$ fucoidan supplementation on the large intestinal microbiota was determined using next-generation sequencing of the $16 \mathrm{~S}$ rRNA gene, using the Illumina MiSeq platform as detailed in the materials and methods. Bioinformatic analysis, as described in the materials and methods, allowed for the identification of 975 OTUs. The full $16 \mathrm{~S}$ rRNA microbial analysis data for both the caecum and colon are presented in the Supplementary Materials (Supplementary Document 1 and Supplementary Tables S1-S2). 


\subsubsection{Bacterial Richness and Diversity Analysis}

Supplementation with 250 ppm fucoidan had no effect on the observed, Shannon or Simpson measures of alpha diversity $(p>0.10)$ (Supplementary Document 1, Figure S1). In relation to beta diversity, pigs did not cluster based on diet nor region of the large intestine (data not shown). As beta diversity is a measure of between animal variation, this suggests that large variation exists between individuals within treatments in this study.

\subsubsection{Differential Abundance Analysis}

The differential abundances of bacterial taxa at phylum, family, genus and species level are presented as percentages in Supplementary Table S1 (caecal digesta) and Supplementary Table S2 (colonic digesta).

The effect of $250 \mathrm{ppm}$ fucoidan supplementation on the bacterial phyla is presented in Table 3. Bacteroidetes were predominant in both the caecum and colon $(\sim 50 \%-56 \%)$, followed by Firmicutes $(\sim 26 \%-30 \%)$ and Proteobacteria $(\sim 12 \%-19 \%)$. Dietary treatment did not influence the relative abundance of any phylum $(p>0.05)$. Genus-level analysis revealed that Prevotella and Campylobacter were the predominant genera in both the caecal (Table 4) and colonic digesta (Supplementary Table S2). There were no differences in the relative abundance of any OTU in the colon. Within the phylum Firmicutes, four differentially abundant OTUs were identified in the caecum between the basal and 250 ppm fucoidan groups. One OTU assigned to the genus Turicibacter (368490) $(p<0.01$; Table 4), one OTU assigned to the family Lachnospiraceae (846477) and two others within the class Clostridia $(358439,555945)$ were reduced in fucoidan-supplemented pigs $(p<0.05$; Table 5$)$. Within the phylum Proteobacteria, one OTU assigned to the genus Helicobacter (311173) was increased in the caecal digesta of pigs supplemented with $250 \mathrm{ppm}$ fucoidan $(p<0.01$; Table 4$)$. Within the phylum Bacteroidetes, four differentially abundant OTUs were identified in the caecum. One OTU assigned to the genus Prevotella (261240) was reduced, while one was assigned to the genus Parabacteroides (28974), one assigned to the family RF16 (new feference OTU3588) and one which could not be assigned to any family (299713), were increased in pigs supplemented with $250 \mathrm{ppm}$ fucoidan $(p<0.05$; Table 5$)$.

Table 3. Effect of $250 \mathrm{ppm}$ fucoidan on the relative abundance of bacterial phyla in the caecal and colonic digesta (mean \% relative abundance with their standard errors).

\begin{tabular}{cccccccccc}
\hline & \multicolumn{4}{c}{ Caecum } & & \multicolumn{2}{c}{ Colon } \\
\hline Phylum & Basal * & $\begin{array}{c}\text { Fucoidan } \\
\mathbf{2 5 0} \mathbf{~ p p m} *\end{array}$ & SEM & $\begin{array}{c}\text { Adjusted } \\
p \text {-Value }\end{array}$ & Basal * & $\begin{array}{c}\text { Fucoidan } \\
\text { 250 ppm * }\end{array}$ & $\begin{array}{c}\text { SEM } \\
\begin{array}{c}\text { Adjusted } \\
p \text {-Value }\end{array}\end{array}$ \\
\hline Bacteroidetes & 50.82 & 54.23 & 2.28 & 0.277 & 54.58 & 56.08 & 2.47 & 0.996 \\
\hline Firmicutes & 27.58 & 26.87 & 2.03 & 0.246 & 29.57 & 28.76 & 2.82 & 0.996 \\
\hline Proteobacteria & 19.44 & 16.71 & 2.55 & 0.246 & 12.08 & 12.43 & 2.30 & 0.996 \\
\hline Spirochaetes & 1.53 & 1.43 & 0.49 & 0.859 & 2.49 & 1.83 & 0.57 & 0.670 \\
\hline Deferribacter & 0.21 & 0.18 & 0.06 & 0.859 & 0.61 & 0.42 & 0.21 & 0.996 \\
\hline Fusobacteria & 0.20 & 0.12 & 0.11 & 0.859 & 0.31 & 0.00 & 0.15 & 0.670 \\
\hline Tenericutes & 0.10 & 0.34 & 0.07 & 0.358 & 0.18 & 0.29 & 0.06 & 0.996 \\
\hline Actinobacteria & 0.07 & 0.08 & 0.01 & 0.859 & 0.09 & 0.09 & 0.02 & 0.996 \\
\hline Fibrobacteres & 0.04 & 0.04 & 0.01 & 0.859 & 0.09 & 0.10 & 0.04 & 0.996 \\
\hline
\end{tabular}

* A total of 8 replicates were used per treatment group. 
Table 4. Effect of $250 \mathrm{ppm}$ fucoidan on the relative abundance of bacterial genera in the caecal digesta (mean \% relative abundance with their standard errors).

\begin{tabular}{|c|c|c|c|c|c|}
\hline Genus & OTU & Basal * & $\begin{array}{c}\text { Fucoidan } 250 \\
\text { ppm }\end{array}$ & SEM & $\begin{array}{c}\text { Adjusted } \\
p \text {-Value }\end{array}$ \\
\hline Prevotella & 568118 & 42.73 & 43.91 & 3.49 & 0.911 \\
\hline Campylobacter & 113756 & 14.02 & 13.94 & 2.20 & 0.888 \\
\hline [Prevotella] & 20534 & 11.98 & 11.92 & 1.56 & 0.797 \\
\hline Roseburia & New.CleanUp.ReferenceOTU122441 & 5.23 & 5.26 & 1.38 & 0.985 \\
\hline Lactobacillus & 302975 & 3.71 & 2.57 & 1.07 & 0.797 \\
\hline Faecalibacterium & 851865 & 3.30 & 2.41 & 0.79 & 0.911 \\
\hline Anaerovibrio & New.ReferenceOTU1058 & 2.44 & 2.44 & 0.69 & 0.888 \\
\hline Treponema & 68837 & 1.98 & 1.93 & 0.63 & 0.901 \\
\hline Bacteroides & New.ReferenceOTU2302 & 1.95 & 1.34 & 0.96 & 0.614 \\
\hline CF231 & 300853 & 1.89 & 3.00 & 0.41 & 0.911 \\
\hline Oscillospira & 310886 & 1.87 & 2.29 & 0.21 & 0.955 \\
\hline Succinivibrio & 163857 & 1.80 & 0.89 & 0.76 & 0.183 \\
\hline Actinobacillus & 359779 & 1.50 & 0.73 & 0.57 & 0.614 \\
\hline Lachnospira & 843553 & 0.94 & 0.59 & 0.20 & 0.614 \\
\hline Parabacteroides & 28974 & 0.79 & 1.58 & 0.37 & 0.911 \\
\hline Coprococcus & 1107057 & 0.69 & 0.58 & 0.13 & 0.708 \\
\hline Clostridium & 215963 & 0.42 & 0.32 & 0.10 & 0.880 \\
\hline$Y R C 22$ & 4435235 & 0.37 & 0.55 & 0.14 & 0.968 \\
\hline Ruminococcus & 148925 & 0.35 & 0.35 & 0.06 & 0.888 \\
\hline Fusobacterium & 1654477 & 0.31 & 0.23 & 0.18 & 0.797 \\
\hline Mucispirillum & 4374042 & 0.27 & 0.23 & 0.07 & 0.911 \\
\hline Turicibacter & 368490 & 0.21 & 0.00 & 0.08 & 0.002 \\
\hline Sutterella & 333380 & 0.18 & 0.29 & 0.04 & 0.911 \\
\hline Blautia & 696563 & 0.12 & 0.11 & 0.02 & 0.911 \\
\hline Dorea & 1076587 & 0.09 & 0.13 & 0.02 & 0.797 \\
\hline Mitsuokella & 149335 & 0.08 & 0.06 & 0.03 & 0.911 \\
\hline Desulfovibrio & 30569 & 0.08 & 0.48 & 0.11 & 0.183 \\
\hline Butyrivibrio & 4364564 & 0.08 & 0.03 & 0.03 & 0.797 \\
\hline Streptococcus & 349024 & 0.07 & 0.02 & 0.02 & 0.507 \\
\hline Helicobacter & 311173 & 0.07 & 0.80 & 0.18 & 0.002 \\
\hline Aggregatibacter & 9498 & 0.06 & 0.00 & 0.03 & 0.797 \\
\hline Anaerovorax & 1112364 & 0.05 & 0.01 & 0.02 & 0.888 \\
\hline Megasphaera & 266210 & 0.05 & 0.06 & 0.02 & 0.985 \\
\hline Fibrobacter & New.ReferenceOTU3654 & 0.05 & 0.05 & 0.02 & 0.911 \\
\hline Phascolarctobacterium & 916143 & 0.05 & 0.05 & 0.01 & 0.955 \\
\hline [Ruminococcus] & 1111191 & 0.04 & 0.00 & 0.02 & 0.614 \\
\hline Anaeroplasma & New.ReferenceOTU3606 & 0.04 & 0.22 & 0.07 & 0.911 \\
\hline Epulopiscium & New.ReferenceOTU2736 & 0.03 & 0.01 & 0.01 & 0.911 \\
\hline Collinsella & 363794 & 0.03 & 0.06 & 0.01 & 0.614 \\
\hline Anaerobiospirillum & 587570 & 0.03 & 0.40 & 0.10 & 0.183 \\
\hline$r c 4-4$ & New.ReferenceOTU2707 & 0.02 & 0.03 & 0.01 & 0.911 \\
\hline Anaerostipes & New.ReferenceOTU1761 & 0.01 & 0.01 & 0.00 & 0.708 \\
\hline Slackia & 367139 & 0.00 & 0.02 & 0.01 & 0.614 \\
\hline Acidaminococcus & 25947 & 0.00 & 0.01 & 0.00 & 0.593 \\
\hline Oxalobacter & 360508 & 0.00 & 0.01 & 0.00 & 0.797 \\
\hline Bilophila & New.ReferenceOTU2103 & 0.00 & 0.01 & 0.00 & 0.481 \\
\hline Dialister & 264552 & 0.00 & 0.04 & 0.01 & 0.221 \\
\hline Mycoplasma & 1143674 & 0.00 & 0.07 & 0.03 & \\
\hline
\end{tabular}

OTU, operational taxonomic unit; * A total of 8 replicates were used per treatment group. 
Table 5. Differentially abundant OTUs in the caecum of pigs fed a basal diet supplemented with 250 ppm fucoidan. A negative log2FoldChange indicates a reduction, while a positive log2FoldChange indicates an increase in abundance in the $250 \mathrm{ppm}$ fucoidan group compared to the basal group $(\mathrm{n}=$ 8/treatment).

\begin{tabular}{|c|c|c|c|c|c|c|}
\hline & OTU & BaseMean & Log2FoldChange & lfcSE & Stat & $\begin{array}{c}\text { Adjusted } \\
p \text {-Value }\end{array}$ \\
\hline \multicolumn{7}{|c|}{ Class } \\
\hline Clostridia & 358439 & 88.53 & -3.432 & 1.040 & -3.299 & 0.039 \\
\hline Bacteroidia & 299713 & 267.65 & 7.458 & 2.119 & 3.520 & 0.039 \\
\hline Clostridia & 555945 & 33.80 & -4.596 & 1.327 & -3.464 & 0.039 \\
\hline \multicolumn{7}{|c|}{ Family } \\
\hline Lachnospiraceae & 846477 & 50.79 & -3.815 & 1.182 & -3.227 & 0.039 \\
\hline RF16 & New.ReferenceOTU3588 & 309.62 & 3.792 & 1.128 & 3.362 & 0.039 \\
\hline \multicolumn{7}{|c|}{ Genus } \\
\hline Prevotella & 261240 & 246.06 & -4.086 & 1.255 & -3.256 & 0.039 \\
\hline Parabacteroides & 28974 & 311.19 & 3.027 & 0.942 & 3.215 & 0.039 \\
\hline Turicibacter & 368490 & 16.56 & -4.215 & 1.171 & -3.599 & 0.039 \\
\hline
\end{tabular}

OTU, operational taxonomic unit; lfsce, logfoldchange standard error; stat, wald statistic.

\subsubsection{Selected Microbial Populations in the Caecal and Colonic Digesta}

The effect of supplementation with $250 \mathrm{ppm}$ fucoidan on the populations of selected microbial species in the caecum and colon were measured using QPCR; the results are presented in Table 6. Dietary supplementation with 250 ppm fucoidan had no effect on the numbers of Bifidobacterium spp., Lactobacillus spp., Enterobacteriaceae or total bacteria in either the caecum or colon.

Table 6. Effect of $250 \mathrm{ppm}$ fucoidan on selected microbial populations in the caecum and colon (least square means with their standard errors).

\begin{tabular}{ccccc}
\hline & Basal $^{*}$ & Fucoidan 250 ppm * & SEM & $p$-Value \\
\hline & Caecal bacterial numbers Log GCN/g digesta & \\
\hline Bifidobacterium spp. & 6.53 & 6.48 & 0.078 & 0.676 \\
\hline Lactobacillus spp. & 8.34 & 8.31 & 0.219 & 0.938 \\
\hline Enterobacteriaceae & 8.30 & 8.08 & 0.277 & 0.613 \\
\hline Total bacteria & 8.90 & 8.77 & 0.133 & 0.456 \\
\hline Colonic bacterial numbers Log GCN/g digesta & 0.363 & 0.389 \\
\hline Bifidobacterium spp. & 5.57 & 5.50 & 0.135 & 0.847 \\
\hline Lactobacillus spp. & 8.19 & 8.14 & 0.295 & 0.684 \\
\hline Enterobacteriaceae & 8.32 & 8.14 & 0.105 & 0.219 \\
\hline Total bacteria & 9.25 & 9.07 &
\end{tabular}

GCN, gene copy numbers. ${ }^{*}$ A total of 8 replicates were used per treatment group.

\subsubsection{VFA}

VFA concentrations were measured in both the caecal and colonic digesta, as described in the materials and methods, to determine the effect of supplementation with 250 ppm fucoidan on microbial fermentation in the large intestine. The concentrations of the measured VFA are presented in Table 7. Fucoidan inclusion at $250 \mathrm{ppm}$ had no effect on VFA in the caecum. In the colon, fucoidan supplementation increased the concentration of total VFA $(p<0.05)$, propionate $(p<0.01)$ and valerate $(p<0.05)$. Fucoidan supplementation also exhibited a tendency to increase butyrate $(p<0.10)$ concentration. 
Table 7. Effect of fucoidan inclusion of VFA in $\mathrm{mmol} / \mathrm{g}$ digesta in the caecum and colon (least square means with their standard errors).

\begin{tabular}{|c|c|c|c|c|}
\hline & Basal * & Fucoidan $250 \mathrm{ppm} *$ & SEM & $p$-Value \\
\hline \multicolumn{5}{|c|}{ Caecal mmol/g digesta } \\
\hline Acetate & 92.58 & 92.05 & 3.55 & 0.918 \\
\hline Propionate & 19.85 & 21.71 & 1.28 & 0.322 \\
\hline Butyrate & 12.76 & 12.23 & 1.44 & 0.798 \\
\hline Isobutyrate & 0.63 & 0.36 & 0.11 & 0.093 \\
\hline Valerate & 1.27 & 1.36 & 0.15 & 0.695 \\
\hline Isovalerate & 0.45 & 0.40 & 0.05 & 0.470 \\
\hline Total VFA & 127.55 & 128.11 & 4.73 & 0.935 \\
\hline Branched chain VFA's & 2.36 & 2.12 & 0.19 & 0.380 \\
\hline \multicolumn{5}{|c|}{ Colonic mmol/g digesta } \\
\hline Acetate & 95.36 & 106.06 & 4.85 & 0.146 \\
\hline Propionate & 19.05 & 24.86 & 1.33 & 0.009 \\
\hline Butyrate & 12.64 & 19.72 & 2.58 & 0.077 \\
\hline Isobutyrate & 1.04 & 0.95 & 0.23 & 0.804 \\
\hline Valerate & 1.72 & 3.25 & 0.37 & 0.012 \\
\hline Isovalerate & 0.90 & 1.02 & 0.15 & 0.571 \\
\hline Total VFA & 130.71 & 155.86 & 7.81 & 0.042 \\
\hline Branched chain VFA's & 3.66 & 5.23 & 0.62 & 0.097 \\
\hline
\end{tabular}

VFA, volatile fatty acids. ${ }^{*} \mathrm{~A}$ total of eight replicates were used per treatment group.

\subsection{Gene Expression}

The Nanostring nCounter was employed to examine the effect of fucoidan on the expression of genes related to intestinal health and functionality. The expression profile of 32 genes in the small intestine and 53 genes in the large intestine were measured, as described in the materials and methods. The genes that were differentially expressed are presented in Table 8, with all gene expression data presented in the Supplementary Materials (Supplementary Document 1, Tables S1-S4).

Table 8. Effect of supplementation with $250 \mathrm{ppm}$ fucoidan on the expression of genes involved in nutrient digestion and transport in the small intestine and the expression of genes involved in immune responses and intestinal integrity in the small intestine and colon (least square means with their standard errors).

\begin{tabular}{|c|c|c|c|c|c|}
\hline Region & Gene & Basal * & Fucoidan 250 ppm * & SEM & $p$-Value \\
\hline \multicolumn{6}{|c|}{ Nutrient transporters and digestive enzymes } \\
\hline Duodenum & SLC5A8 & 3214.00 & 4059.56 & 199.78 & 0.010 \\
\hline \multirow{3}{*}{ Jejunum } & SLC15A1 & 1218.79 & 648.81 & 190.18 & 0.054 \\
\hline & SLC5A1 & 7466.46 & 2564.99 & 937.75 & 0.003 \\
\hline & SI & 20997.41 & 8785.56 & 3261.91 & 0.020 \\
\hline \multirow{2}{*}{ Ileum } & $F A B P 2$ & 13068.53 & 8027.51 & 1440.41 & 0.025 \\
\hline & $S L C 5 A 1$ & 14956.02 & 9008.17 & 1924.65 & 0.044 \\
\hline \multicolumn{6}{|c|}{ Markers of immune response and intestinal integrity } \\
\hline Duodenum & CLDN5 & 65.53 & 55.71 & 3.18 & 0.047 \\
\hline Ileum & TJP1 & 1159.5 & 987.10 & 55.73 & 0.044 \\
\hline \multirow{2}{*}{ Colon } & DDX58 & 2789.66 & 1829.72 & 232.24 & 0.011 \\
\hline & TRAF3 & 152.82 & 130.90 & 7.12 & 0.047 \\
\hline
\end{tabular}

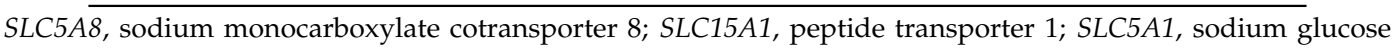
cotransporter 1; SI, sucrase isomaltase; $F A B P 2$, fatty acid binding protein 2; CLDN5, claudin 5; TJP1, tight junction protein 1; DDX58, retinoic acid inducible gene 1; TRAF3, TNF receptor associated factor $3 .{ }^{*}$ A total of 8 replicates were used per treatment group. 
Digestive Enzyme and Nutrient Transporter Gene Expression

In the duodenum, fucoidan supplementation at $250 \mathrm{ppm}$ upregulated sodium monocarboxylate cotransporter $(S L C 5 A 8 ; p<0.05)$. In the jejunum, the largest fold changes $(F C)$ were observed in response to fucoidan supplementation which downregulated peptide transporter 1 (SLC15A1; $p=0.05$, $F C=1.9)$, sodium glucose cotransporter $1(S L C 5 A 1 ; p<0.01, F C=2.9)$ and sucrase-isomaltase $(S I ; p<$ $0.05, F C=2.4)$. In the ileum, fucoidan supplementation at $250 \mathrm{ppm}$ downregulated fatty acid binding protein $2(F A B P 2 ; p<0.05, F C=1.6)$ and $\operatorname{SLC} 5 A 1(p<0.05, F C=1.7)$.

\subsection{Immune Marker, Tight Junctions and Transcription FactorGene Expression}

In the duodenum, fucoidan supplementation at $250 \mathrm{ppm}$ downregulated the tight junction gene claudin-5 (CLDN5; $p<0.05)$, and in the ileum, fucoidan supplementation reduced the expression of tight junction protein $1(T J P 1 ; p<0.05)$.

In the colon, fucoidan supplementation downregulated the expression of TNF receptor associated factor 3 (TRAF3; $p<0.05)$ and retinoic acid inducible gene $1(D D X 58 ; p<0.05)$.

\section{Discussion}

In this study, we hypothesised that the optimum inclusion level of fucoidan from a $44 \%$ fucoidan extract from the species Ascophyllum nodosum would favourably enhance the large intestinal microbiota and reduce the incidence of post-weaning diarrhoea. For the duration of this study, faecal scores of all treatment groups remained within a healthy range, which is likely due to the good hygiene conditions and husbandry practices often observed in research facilities compared with commercial farms [22]. However, supplementation with $250 \mathrm{ppm}$ fucoidan did result in a significant improvement in faecal scores. These healthier faecal scores, in association with greater concentrations of VFAs in the colon, suggest that these fucoidan-supplemented pigs had a healthier digestive tract. While it had been anticipated that the fucoidan rich extract may negatively impact performance, neither inclusion level significantly influenced growth performance; in fact, pigs supplemented with $250 \mathrm{ppm}$ fucoidan had numerically higher ADG, ADFI and G:F. Despite the reduced expression of some nutrient transporters in the small intestine with the inclusion of $250 \mathrm{ppm}$ fucoidan, this was not associated with any disimprovements in small intestinal morphology or growth performance. These results indicate that dietary inclusion of $250 \mathrm{ppm}$ fucoidan from a $44 \%$ purified fucoidan extract from Ascophyllum nodosum can improve faecal consistency in pigs during the post-weaning period. Further studies to ascertain the ability of this extract to prevent post-weaning diarrhoea in pigs reared in more challenging hygiene or husbandry conditions are warranted.

The main hypothesis of this study is that fucoidan supplementation would enhance the large intestinal microbiota. Dietary supplementation with fucoidan previously increased lactobacilli numbers in the faeces $[14,15]$ and also in the proximal and distal colon [13] of pigs. Surprisingly, while faecal consistency was improved and colonic VFA concentrations were increased, fucoidan supplementation had no effect on the colonic microbiota in this study. These contrasting responses to fucoidan supplementation may be related to the species of seaweed from which the fucoidan was derived. Ascophyllum nodosum was used in this study while the aforementioned studies in which increases in lactobacilli were observed used fucoidan derived from Laminaria spp. Fucoidans can be classified into two groups, those with long chains of $(1 \rightarrow 3)$-linked $\alpha$-l-fucopyranosyl as found in Laminaria spp., and those with alternating $(1 \rightarrow 3)$ - and $(1 \rightarrow 4)$-linked $\alpha$-l-fucopyranosyl residues [8] found in Ascophyllum nodosum and Fucus spp. Thus, these differing structures may explain the varying responses to fucoidan supplementation among studies. However, beyond species differences, the biological activities of the extract can also differ depending on the season of harvest and also due to the extraction methodology and conditions employed such as solvent, $\mathrm{pH}$, time and pressure [18]. Previously, the methods used for measuring the bacterial populations varied from traditional culture methods to QPCR 
compared with $16 \mathrm{~S}$ rRNA sequencing used in this study; this difference may also have contributed to the differing outcomes.

Both QPCR and 16S rRNA sequencing were utilized to analyse the effects of fucoidan on the large intestinal bacterial community. In the caecum, fucoidan had no effect on the relative bacterial abundance at phylum, class, family or species level. Bacteroidetes, Firmicutes and Proteobacteria were the predominant phyla observed in both groups of pigs, and these have previously been identified as the predominant phyla in both suckling and weaned pigs $[23,24]$. Consistent with previous reports, Prevotella was identified as the predominant genus in both groups; this genus is associated with the introduction of a plant-based diet due to their ability to degrade hemicelluloses such as xylans present in plants $[23,24]$. One OTU assigned to the genus Prevotella was reduced in fucoidan-supplemented pigs; however, other OTUs assigned to this genus were not affected. Fucoidan also reduced the relative abundance of OTUs within the phylum Firmicutes, two assigned to the class clostridia and one assigned to the family Lachnospiraceae. This family is associated with the production of butyrate, in particular, Roseburia spp. Species belonging to Lachnospiraceae can convert lactate into butyrate [25]. While there were no changes in the relative abundance of bacterial communities within the colon, the concentration of propionate, valerate, butyrate and total VFA were higher in pigs supplemented with fucoidan. Propionate is produced from highly fermentable carbohydrates and sugars, acetate and butyrate are associated with the fermentation of fibre [26], and valerate is formed through the fermentation of undigested/unabsorbed protein or endogenous protein [27]. VFA are involved in the maintenance of colonic homeostasis; in particular, butyrate is the preferential energy source of the colonocytes accounting for about $70 \%$ of total energy consumption [27]. VFA also have antidiarrheal effects as they promote the absorption of sodium and water [27,28]; thus, the increased VFA concentrations may be related to the improved faecal scores in the pigs supplemented with fucoidan.

Supplementation with $250 \mathrm{ppm}$ fucoidan downregulated the gene expression of some digestive enzymes and nutrient transporters in the small intestine. This group had a 2.4-fold reduction in SI, an enzyme complex involved in the final digestion of disaccharides and oligosaccharides to absorbable monosaccharides. SI expression was previously shown to be upregulated in the rat jejunum following a sucrose diet suggesting its expression is regulated by dietary carbohydrates [29]. Similar to this reduction in SI, in vitro fucoidans from Ascophyllum nodosum were shown to suppress $\alpha$-amylase (salivary) and $\alpha$-glucosidase [30]. The ability of fucoidan to reduce $\alpha$-amylase was shown to be dependent on its molecular weight and degree of sulphation [31]. Following digestion, nutrient transporters enable the transfer of digestion products (monosaccharides, peptides, amino acids and fatty acids) from the lumen into the enterocytes [32]. In this study the expression of SLC5A1/SGLT1 (jejunum and ileum) which transports glucose [33], SLC15A1/PEPT1 (jejunum) which transports di- and tri-peptides [34] and FABP2 (ileum) which transports long chain fatty acids [35] were all downregulated $(2.9-, 1.7-, 1.9-, 1.6-$ fold, respectively) following fucoidan supplementation. The reduction in the gene expression of digestive enzymes and nutrient transporters may be due to the presence of both fucoidan and alginate in the extract. Fucoidan is a non-digestible polysaccharide in the upper gastrointestinal tract [36], and by increasing digesta viscosity, it may disrupt the flow of digesta, reducing the mixing of digesta with digestive fluids. Similarly, alginate is a viscous soluble fibre which can delay gastric emptying through the formation of gels within the stomach and affect the rheological properties of the digestive contents [37]. As the gene expression of nutrient transporters can be modified by fluctuations in available nutrients [38], it is possible the presence of fucoidan and/or alginate within the intestine may have led to the downregulation of nutrient transporters in the supplemented group. Unfortunately, ileal digestibility's could not be measured in this study due to a lack of digesta in the ileum at the time of sampling. This may have enhanced our understanding of the effects of the various components of the fucoidan-rich extract on nutrient digestion and absorption as the changes in gene expression were not coupled with changes in villus architecture or growth performance. Perhaps there are other mechanisms at play which have offset the effects of the downregulated nutrient transporter genes in terms of overall growth performance. 
The pig is a commonly used model for studying the effects of dietary supplements within the gastrointestinal tract due to its anatomical, physiological and functional similarities with humans [39]. As fucoidan is widely investigated for use in the prevention/treatment of metabolic syndromes, including obesity and diabetes (Wang, et al. [40]), the results from this study may provide relevant information for future studies. In this study, the fucoidan rich extract reduced the ileal expression of FABP2. Similarly, fucoidan reduced the expression of fatty acid binding protein 4 (FABP4) in vitro in 3T2-L1 adipocytes [41], suggesting that fucoidan has the potential to reduce fatty acid absorption in different cell types. Fucoidan-supplemented pigs also had increased colonic propionate. Previously, propionate increased the secretion of the appetite-regulating hormones PYY and GLP-1 [42] in-vitro in cultured colonic cells [42]. Furthermore, short term dietary supplementation with an inulin propionate ester increased PYY and GLP-1 secretion in the colon and reduced feed intake, while long term supplementation reduced weight gain and intra-abdominal fat deposition in overweight adults [42]. It has also been suggested that fucoidan can influence glucose metabolism [40]. As mentioned above, the gene expression of SI and SGLT1 were downregulated in pigs supplemented with a fucoidan-rich extract, indicating fucoidan may have the potential to reduce the accessibility of dietary carbohydrates. This aligns with the aforementioned in-vitro reduction of $\alpha$-amylase and $\alpha$-glucosidase with fucoidan derived from Ascophyllum nodosum, while fucoidan derived from Fucus vesiculosus only inhibited $\alpha$-glucosidase [30], suggesting Ascophyllum nodosum is a better source of fucoidan for the prevention of Type 2 diabetes. Ganesan et al. [43] suggested the inhibitory activities of fucoidan on glucose metabolism may be related to the interaction between the negatively charged sulphate groups of fucoidan and digestive enzymes or may be related to the high viscosity of fucoidan influencing the accessibility of nutrients to digestive enzymes. Thus, the reduced gene expression of fatty acid and glucose transporters, digestive enzymes and increased colonic propionate suggest fucoidan warrants further study as a dietary supplement for the prevention or treatment of metabolic diseases such as obesity and diabetes.

\section{Materials and Methods}

All experimental procedures described in this work were approved under the University College Dublin Animal Research Ethics Committee (AREC-17-19-O'Doherty) and were conducted in accordance with Irish legislation (SI no. 543/2012) and the EU directive 2010/63/EU for animal experimentation.

\subsection{Experimental Design and Diets}

This experiment comprised 3 dietary treatments: (T1) basal diet; (T2) basal diet + 125 ppm fucoidan; (T3) basal diet $+250 \mathrm{ppm}$ fucoidan. Previously, fucoidan demonstrated beneficial effects at an inclusion level of 240 ppm $[9,13,14]$; however, its effects at lower inclusion levels were unknown. Thus, the fucoidan dietary treatments were formulated to contain either 125 or $250 \mathrm{ppm}$ fucoidan. Seventy-two healthy piglets (progeny of meatline boars $\times$ (large white $\times$ landrace sows)) with an average weaning weight of $8.4 \mathrm{~kg}$ (SD 1.06) were sourced from a commercial farm at weaning (28 days of age) and housed in pens of three. The pigs were blocked based on weaning weight, the litter of origin and sex and, within each block, assigned to one of the three dietary treatments (eight replicates/treatment). The basal diet contained $14.95 \mathrm{MJ} / \mathrm{kg}$ digestible energy, $190 \mathrm{~g} / \mathrm{kg}$ crude protein (CP) and $13.5 \mathrm{~g} / \mathrm{kg}$ total lysine. All amino acid requirements were met relative to lysine [44]. The ingredient and chemical analysis of the dietary treatments is presented in Table 9. The fucoidan rich extract was a commercial product sourced from BioAtlantis Ltd (Clash Industrial Estate, Tralee, Co. Kerry, Ireland). A single extraction was performed from Ascophyllum nodosum to produce the commercial product which contained $441 \mathrm{~g}$ of fucoidan per $\mathrm{kg}$ DM, $25.9 \mathrm{~g}$ laminarin $/ \mathrm{kg}$ DM, $135 \mathrm{~g}$ alginates $/ \mathrm{kg} \mathrm{DM}, 43.8 \mathrm{~g}$ mannitol $/ \mathrm{kg}$ DM, $34.8 \mathrm{~g}$ phlorotannins $/ \mathrm{kg}$ DM and $319.5 \mathrm{~g}$ ash $/ \mathrm{kg}$ DM. The appropriate quantity of the fucoidan rich extract was added to the basal diet to achieve 125 or 250 ppm fucoidan inclusion levels. 
Table 9. Ingredient and chemical composition of basal diet *

\begin{tabular}{|c|c|}
\hline \multicolumn{2}{|l|}{ Ingredient (g/kg) } \\
\hline Wheat & 340.0 \\
\hline Full fat soya & 170.0 \\
\hline Flaked wheat & 130.0 \\
\hline Soya bean meal & 105.0 \\
\hline Flaked maize & 70.0 \\
\hline Whey powder & 50.0 \\
\hline Soya oil & 65.0 \\
\hline Vitamins and minerals ${ }^{a}$ & 2.5 \\
\hline Sodium bicarbonate & 2.0 \\
\hline Mono calcium phosphate & 4.0 \\
\hline Calcium carbonate (Limestone) & 6.0 \\
\hline Salt & 2.0 \\
\hline Lysine HCL & 4.0 \\
\hline DL-methionine & 1.5 \\
\hline L-threonine & 1.5 \\
\hline \multicolumn{2}{|l|}{ Chemical analysis } \\
\hline $\mathrm{DM}$ & 866.1 \\
\hline Crude protein $(\mathrm{N} \times 6.25)$ & 190 \\
\hline Digestible energy $(\mathrm{MJ} / \mathrm{kg})^{\dagger}$ & 14.95 \\
\hline Ash & 48.4 \\
\hline Neutral detergent fibre & 114.00 \\
\hline Lysine $^{+}$ & 13.5 \\
\hline Methionine and cysteine ${ }^{\dagger}$ & 7.4 \\
\hline Threonine $^{+}$ & 7.9 \\
\hline Tryptophan $^{\dagger}$ & 2.6 \\
\hline Calcium $^{\dagger}$ & 7.2 \\
\hline Phosphorous $^{+}$ & 6.0 \\
\hline
\end{tabular}

\footnotetext{
* Treatments: (1) basal diet; (2) basal diet + 125 parts per million (ppm) fucoidan; (3) basal diet +250 ppm fucoidan. ${ }^{+}$Calculated for tabulated nutritional composition [45]. ${ }^{a}$ Provided (mg/kg complete diet): $\mathrm{Cu}, 100 ; \mathrm{Fe}, 140 ; \mathrm{Mn}, 47$; $\mathrm{Zn}, 120$; I, 0.6; Se, 0.3; retinol, 1.8; cholecalciferol, 0.025; $\alpha$-tocopherol, 67; phytylmenaquinone, 4; cyanocobalamin, 0.01; riboflavin, 2; nicotinic acid, 12; pantothenic acid, 10; choline chloride, 250; thiamine, 2; pyridoxine, 0.015 . Celite included at $300 \mathrm{mg} / \mathrm{kg}$ complete diet.
}

\subsection{Housing and Animal Management}

The pigs were housed in fully slatted pens $(1.7 \times 1.2 \mathrm{~m})$. Pigs were weighed at the beginning of the experiment (d0; day of weaning) and on days 7 and 14 . The ambient environmental temperature within the house was thermostatically controlled at $30^{\circ} \mathrm{C}$ for the first 7 days and then reduced by $2{ }^{\circ} \mathrm{C}$ for the remainder of the second week, and the humidity was maintained at $65 \%$. Feed in meal form and water were available ad libitum from four-space feeders and nipple drinkers; precaution was taken to avoid wastage of feed. Everyday throughout the experiment, faecal scores were recorded in the individual pens by the same operator on a scale ranging from 1 to 5 as follows: $1=$ hard, firm faeces; 2 = slightly soft faeces; 3 = soft, partially formed faeces; 4 = loose, semi-liquid faeces; and $5=$ watery, mucous-like faeces [14]. 


\subsection{Sample Collection}

On day 15, eight pigs (one pig/pen) from the basal group and best performing fucoidan treatment (250 ppm) group (based on FS) received a lethal injection with pentobarbitone sodium (euthatal solution, $200 \mathrm{mg} / \mathrm{mL}$; Merial Animal Health, Essex, UK) at a rate of $0.71 \mathrm{~mL} / \mathrm{kg}$ BW to the cranial vena cava to humanely sacrifice the animals. Euthanasia was completed by a trained individual in a separate room from the other pigs. The entire intestinal tract was removed immediately. Sections from the duodenum (10 cm from the stomach), the jejunum $(60 \mathrm{~cm}$ from the stomach) and the ileum $(15 \mathrm{~cm}$ from the caecum) were excised and fixed in 10\% phosphate-buffered formalin. Digesta from the caecum and colon was collected in sterile containers (Sarstedt, Wexford, Ireland) and frozen immediately for further analysis. In addition, tissue samples were taken from the duodenum, jejunum, ileum and colon to establish relative gene expression of a range of functional categories, including cytokines, digestive enzymes, nutrient transporters, mucins, tight junction components, pathogen recognition receptors, transcription regulators, appetite regulators, growth factors, kinases, ligand-dependent nuclear receptors, suppressors of cytokine signalling, peptidases, transmembrane receptors and viral defence genes. Relative gene expression was measured using the Nanostring nCounter. Tissue sections of $1 \mathrm{~cm}^{2}$ from the duodenum, jejunum, ileum, and colon were excised, emptied by dissecting them along the mesentery and rinsed using sterile PBS (Oxoid, Hampshire, UK). The tissue sections were stripped of overlying smooth muscle and stored in $5 \mathrm{~mL}$ RNAlater ${ }^{\circledR}$ solution (Applied Biosystems, Foster City, CA, USA) overnight at $4{ }^{\circ} \mathrm{C}$. The RNAlater ${ }^{\circledR}$ was then removed before storing the samples at $-80^{\circ} \mathrm{C}$.

\subsection{Feed Analysis}

The feed samples were milled through a $1 \mathrm{~mm}$ screen (Christy and Norris hammer mill, Ipswich, UK). The dry matter (DM) of the feed was determined after drying overnight at $104{ }^{\circ} \mathrm{C}$. Crude ash content was determined after the ignition of a known weight of concentrate in a muffle furnace (Nabertherm, Bremen, Germany) at $550^{\circ} \mathrm{C}$ for $6 \mathrm{~h}$. The crude protein $(\mathrm{CP})$ content was determined as Kjeldahl $\mathrm{N} \times 6.25$ using the LECO FP 528 instrument. The neutral detergent fibre (NDF) content was determined according to Van Soest et al. [46].

\subsection{Gut Morphological Analysis}

Preserved duodenal, jejunal and ileal tissue samples were prepared using standard paraffin-embedding techniques. The samples were sectioned at a thickness of $5 \mu \mathrm{m}$ and stained with haematoxylin and eosin. Villus height $(\mathrm{VH})$ and crypt depth $(\mathrm{CD})$ were measured in the stained sections $(4 \times$ objective) using a light microscope fitted with an image analyser (Image-Pro Plus; Media Cybernetics, Oxon, UK. Measurements of 15 correctly orientated and intact villi and crypts were taken for each segment. The $\mathrm{VH}$ was measured from the crypt-villus junction to the tip of the villus, and $\mathrm{CD}$ was measured from the crypt-villus junction to the base. Results are expressed as mean VH or CD in $\mu \mathrm{m}$.

\subsection{Gene Expression}

\subsubsection{RNA Extraction}

Total RNA was extracted from duodenal, jejunal, ileal and colonic tissue using TRIreagent (Sigma-Aldrich, St. Louis, MS, USA) according to the manufacturer's instructions. The crude RNA extract was further purified using the GenElute Mammalian Total RNA miniprep kit (Sigma-Aldrich) according to the manufacturer's instructions. A DNase step was included using an on-Column Dnase 1 digestion set (Sigma-Aldrich, St. Louise, MS, USA). The total RNA was quantified using the Nanodrop-ND1000 spectrophotometer (Thermo Fisher Scientific, Wilmington, USA) and purity was assessed by determining the ratio of the absorbance at 260 and $280 \mathrm{~nm}$. All total RNA samples had 260:280 nm ratios above 2.0. 


\subsubsection{Nanostring nCounter Analysis}

The small intestinal (duodenal, jejunal and ileal) tissues and colonic tissue were analysed using the Nanostring nCounter analysis system (Nanostring Technologies, Seattle, WA, USA). Two custom nCounter panels, one for the small intestine and one for the colon were designed by our group and manufactured by Nanostring (Nanostring Technologies, Seattle, USA). The panel for the small intestine is presented in Table 10 and containes 32 target genes and 5 reference genes. The genes measured in the colon are presented in Table 11; this codeset contained 53 target genes and 8 reference genes. Both panels contained 6 positive and 8 negative controls.

Table 10. Panel of genes analysed in the small intestine.

\begin{tabular}{|c|c|c|}
\hline Group & Gene & Accession \\
\hline \multirow{13}{*}{ Nutrient transporters } & SLC15A1 & NM_214347.1 \\
\hline & SLC5A1 & NM_001164021.1 \\
\hline & $S L C 2 A 1$ & XM_003482115.1 \\
\hline & SLC2A2 & NM_001097417.1 \\
\hline & SLC2A5 & XM_021095282.1 \\
\hline & $S L C 2 A 7$ & XM_003127552.3 \\
\hline & $S L C 2 A 8$ & XM_003480608.1 \\
\hline & $F A B P 2$ & NM_001031780.1 \\
\hline & SLC16A10 & XM_021091212.1 \\
\hline & SLC6A19 & XM_003359855 \\
\hline & SLC7A1 & NM_001012613.1 \\
\hline & SLC5A8 & NM_001291414 \\
\hline & SLC16A1 & NM_001128445.1 \\
\hline \multirow{3}{*}{ Appetite regulators } & CCK & NM_214237.2 \\
\hline & GLP2R & NM_001246266.1 \\
\hline & GCG & NM_214324 \\
\hline \multirow{2}{*}{ Digestive enzymes } & $S I$ & XM_021069748 \\
\hline & CNDP1 & NM_001290324.1 \\
\hline \multirow{5}{*}{ Inflammatory markers } & NFKB1 & NM_001048232.1 \\
\hline & CXCL8 & NM_213867.1 \\
\hline & TGFB1 & NM_214015.2 \\
\hline & $I F N G$ & NM_213948.1 \\
\hline & $I L 1 A$ & NM_214029.1 \\
\hline \multirow{4}{*}{ Tight junctions } & TJP1 & XM_005659811.1 \\
\hline & OCLN & NM_001163647.2 \\
\hline & CLDN3 & NM_001160075.1 \\
\hline & CLDN5 & NM_001161636.1 \\
\hline \multirow{3}{*}{ Toll-like receptors } & TLR2 & NM_213761.1 \\
\hline & TLR4 & NM_001113039.2 \\
\hline & TLR5 & NM_001348771.1 \\
\hline \multirow{2}{*}{ Mucins } & MUC1 & XM_013997019 \\
\hline & MUC2 & XM_013989745 \\
\hline \multirow{5}{*}{ Reference } & $A C T B$ & XM_003124280.4 \\
\hline & $B 2 M$ & NM_213978.1 \\
\hline & GAPDH & NM_001206359.1 \\
\hline & PPIA & NM_214353.1 \\
\hline & HPRT & NM_001032376.2 \\
\hline
\end{tabular}

SLC15A1, peptide transporter 1; SLC5A1, sodium glucose cotransporter; SLC2A1, glucose transporter 1; SLC2A2, glucose transporter 2; $S L C 2 A 5$, glucose transporter 5; $S L C 2 A 7$, glucose transporter 7; $S L C 2 A 8$, glucose transporter 8; FABP2, fatty acid binding protein 2; SLC16A10, aromatic amino acid transporter; SLC6A19, neutral amino acid transporter; SLC7A1, cationic amino acid transporter; SLC5A8, sodium-coupled monocarboxylate transporter; SLC16A1, monocarboxylate transporter 1; CCK, cholecystokinin; GLP2R, glucagon-like peptide 2 receptor; GCG, glucagon; SI, sucrase isomaltase; CNDP1, carnosine dipeptidase; NFKB1, nuclear factor kappa B subunit 1; CXCL8, C-X-C motif chemokine ligand 8; TGFB1, transforming growth factor beta 1; IFNG, interferon gamma; IL1A, interleukin 1A; TJP1, tight junction protein 1; OCLN, occludin; CLDN3, claudin 3; CLDN5, claudin 5; TLR2, toll-like receptor 2; TLR4, toll-like receptor 4; TLR5, toll-like receptor 5; MUC1, mucin 1; MUC2, mucin 2; ACTB, actin beta; $B 2 M$, beta-2-microglobulin; GAPDH, glyceraldehyde-3-phosphate dehydrogenase; PPIA, peptidylprolyl isomerase A; HPRT, hypoxanthine phosphoribosyltransferase 1. 
Table 11. Panel of genes analysed in the colon.

\begin{tabular}{|c|c|c|}
\hline Group & Genes & Accession \\
\hline \multirow{4}{*}{ Cytokines } & CXCL8 & NM_213867.1 \\
\hline & IL1A & NM_214029.1 \\
\hline & $I L 1 B$ & NM_214055.1 \\
\hline & IFNG & NM_213948.1 \\
\hline \multirow{6}{*}{ Enzymes } & $A O A H$ & XM_021079244.1 \\
\hline & CASP1 & NM_214162.1 \\
\hline & PMRT5 & NM_001160093.1 \\
\hline & TRAF2 & XM_005652719.1 \\
\hline & TRAF3 & XM_005666443.2 \\
\hline & TRAF6 & NM_001105286.1 \\
\hline \multirow{8}{*}{ Kinase } & СНUК & NM_001114279.1 \\
\hline & PRKAA1 & NM_001167633.1 \\
\hline & MAPK1 & NM_001198922.1 \\
\hline & MAP3K7 & NM_001114280.1 \\
\hline & RIPK2 & XM_021089139.1 \\
\hline & MTOR & XM_003127584.6 \\
\hline & SYK & NM_001104952.1 \\
\hline & $J A K 2$ & NM_214113.1 \\
\hline \multirow{3}{*}{ Tight junctions } & $\mathrm{CDH} 2$ & XM_021096205.1 \\
\hline & OCLN & NM_001163647.2 \\
\hline & TJP1 & XM_005659811.1 \\
\hline \multirow{3}{*}{ Mucins } & MUC1 & XM_021089728.1 \\
\hline & MUC2 & XM_021082584.1 \\
\hline & MUC4 & NM_001206344.2 \\
\hline \multirow{7}{*}{ Pathogen recognition receptors } & TLR1 & NM_001031775.1 \\
\hline & $T L R 2$ & NM_213761.1 \\
\hline & TLR4 & NM_001113039.2 \\
\hline & TLR6 & NM_213760.1 \\
\hline & TLR7 & NM_001097434.1 \\
\hline & TLR8 & NM_214187.1 \\
\hline & $M A V S$ & NM_001097429.1 \\
\hline Ligand dependent nuclear receptor & PPARG & NM_214379.1 \\
\hline \multirow{2}{*}{ Suppresser of cytokine signalling } & SOCS1 & NM_001204768.1 \\
\hline & SOCS3 & NM_001123196.1 \\
\hline
\end{tabular}


Table 11. Cont.

\begin{tabular}{|c|c|c|}
\hline Group & Genes & Accession \\
\hline \multirow{3}{*}{ Matrix metalloproteinases } & MMP2 & NM_214192.2 \\
\hline & MMP3 & NM_001166308.1 \\
\hline & MMP9 & NM_001038004.1 \\
\hline \multirow{10}{*}{ Transcription regulation } & JUN & NM_213880.1 \\
\hline & IRF3 & NM_213770.1 \\
\hline & MYD88 & NM_001099923.1 \\
\hline & NFKB1 & NM_001048232.1 \\
\hline & PPARGC1A & NM_213963.2 \\
\hline & STAT2 & NM_213889.1 \\
\hline & STAT3 & NM_001044580.1 \\
\hline & TANK & XM_003359533.4 \\
\hline & TIRAP & XM_003130060.4 \\
\hline & TRAM1 & XM_001924618.6 \\
\hline \multirow{4}{*}{ Transmembrane receptor } & CD14 & NM_001097445.2 \\
\hline & CLEC7A & NM_001145866.1 \\
\hline & DDX58 & NM_213804.2 \\
\hline & TICAM1 & NM_001315738.1 \\
\hline \multirow{2}{*}{ Nutrient transporters } & SLC16A1 & NM_001128445.1 \\
\hline & SLC16A7 & XM_003126337.5 \\
\hline \multirow{8}{*}{ Reference } & $A C T B$ & XM_003124280. \\
\hline & $B 2 M$ & NM_213978.1 \\
\hline & GAPDH & NM_001206359.1 \\
\hline & G6PD & XM_021080744.1 \\
\hline & HPRT & NM_001032376.2 \\
\hline & PPIA & NM_214353.1 \\
\hline & RPL19 & XM_003131509.4 \\
\hline & TBP & XM_021085493.1 \\
\hline
\end{tabular}

CXCL8, C-X-C motif chemokine ligand 8; IL1A, interleukin 1A; IL1B, interleukin 1B; IFNG, interferon gamma; $A O A H$, acyloxyacyl hydrolase; CASP1, caspase-1; PRMT5, protein arginine methyltransferase 5; TRAF2, TNF receptor associated factor 2; TRAF3, TNF receptor associated factor 3; TRAF6, TNF receptor associated factor 6; CHUK, component of inhibitor of nuclear factor kappa B kinase complex; PRKAA1, protein kinase AMP-activated catalytic subunit alpha 1; MAPK1, mitogen activate protein kinase $1 ; M A P 3 K 7$, mitogen-activated protein kinase kinase 7; RIPK2, receptor interacting serine/threonine kinase 2; MTOR, mechanistic target of rapamycin kinase; SYK, spleen associated tyrosine kinase; JAK2, janus kinase 2; CDH2, Cadherin 2; OCLN, occludin; TJP1, tight junction protein 1; MUC1, mucin 1; MUC2, mucin 2; MUC4, mucin 4; TLR1, toll-like receptor 1; TLR2, toll-like receptor 2; TLR4, toll-like receptor 4; TLR6, toll-like receptor 6; TLR7, toll-like receptor 7; TLR8, toll-like receptor 8; MAVS, mitochondrial antiviral signalling protein; PPARG, peroxisome proliferator activated receptor gamma; SOCS1, suppressor of cytokine signalling 1; SOCS3, suppressor of cytokine signalling 3; MMP2, matrix metalloproteinase 2; $M M P 3$, matrix metalloproteinase 3; MMP9, matrix metalloproteinase 9; JUN, AP-1 transcription factor subunit; IRF3, interferon regulatory factor 3; MYD88, MYD88 innate immune signal transduction adaptor; NFKB1, nuclear factor kappa B subunit 1; PPARGC1A, PPARG coactivator 1 alpha; STAT2, signal transducer and activator of transcription 2; STAT3, signal transducer and activator of transcription 3; TANK, TRAF family member associated NFKB activator; TIRAP, TIR domain containing adaptor protein; TRAM1, translocation associated membrane protein 1; CD14, CD14 molecule; CLEC7A, C-type lectin domain containing 7A; DDX58, DExD/H-box helicase 58; TICAM1, toll like receptor adaptor molecule 1; SLC16A1, monocarboxylate transporter 1; SLC16A7, monocarboxylate transporter 7; ACTB, actin beta; $B 2 M$, beta-2-microglobulin; GAPDH, glyceraldehyde-3-phosphate dehydrogenase; G6PD, glucose-6-phosphate dehydrogenase; HPRT, hypoxanthine phosphoribosyltransferase 1; PPIA, peptidylprolyl isomerase A, RPL19, ribosomal protein L19; TBP, TATA-box binding protein. 
The expression of all target genes was determined for each sample in a single multiplexed hybridisation reaction, as originally described by Geiss et al. [47]. Briefly, prior to analysis, all samples were measured using the Qubit fluorometer (Thermo Fisher Scientific, Wilmington, USA) and calibrated to $20 \mathrm{ng} / \mu \mathrm{L}$. For the hybridisation reaction, a master mix (MM) was created by adding $70 \mu \mathrm{L}$ of hybridisation buffer to the reporter codeset, as per manufacturer instructions. To each reaction tube, $8 \mu \mathrm{L}$ of MM, $5 \mu \mathrm{L}$ of sample (total RNA concentration $100 \mathrm{ng}$ ) and $2 \mu \mathrm{L}$ capture probeset were added and inverted to mix, then centrifuged briefly before incubation at $65^{\circ} \mathrm{C}$ for $20 \mathrm{~h}$ in a Bio-rad thermocycler (Bio-rad Laboratories Ltd., Watford, Hertfordshire, UK). Post-hybridisation processing was performed within the Nanostring nCounter prep station (Nanostring Technologies, Seattle, USA); this liquid handling system removes excess unbound probes and immobilises samples onto the internal surface of the sample cartridge. Following this, the cartridge is sealed and scanned in the digital analyser (Nanostring Technologies, Seattle, USA), which collects data from the immobilized fluorescent reporters in the sample cartridge. The analysis and normalisation of the raw Nanostring data was performed using nSolver analysis software v4.0 (Nanostring Technologies). Background was corrected for using background thresholding, and a background count level was estimated using the average count of the negative control probes in every reaction plus two standard deviations [48]. Target genes with raw counts below the threshold in more than two-thirds of samples were excluded from the analysis. Raw counts were normalised using a combination of positive control normalisation and CodeSet content normalisation. The former accounts for errors such as pipetting errors, lot-to-lot variation in nCounter preparation plates and nCounter cartridges, while the latter uses housekeeping genes to account for variability in the quantity and quality of sample RNA. Nanostring results (raw and normalised counts) were produced from RCC files using nSolver software v 4.0.

\subsection{Microbiological Analyses}

\subsubsection{Microbial DNA Extraction}

Microbial genomic DNA was extracted from the caecal and colonic digesta samples using a QIAamp DNA stool kit (Qiagen, West Sussex, UK) in accordance with the manufacturer's instructions. The quantity and quality of DNA were assessed using a Nanodrop spectrophotometer (Thermo Fisher Scientific, Wilmington, DE, USA).

\subsubsection{Illumina Sequencing}

High-throughput sequencing of the V3-V4 hypervariable region of the bacterial $16 \mathrm{~S}$ rRNA gene was performed on an Illumina MiSeq platform according to their standard protocols (Eurofins, Wolverhampton, UK). Briefly, the V3-V4 region was PCR-amplified using universal primers containing adapter overhang nucleotide sequences for forward and reverse index primers. Amplicons were purified using AMPure XP beads (Beckman Coulter, Indianapolis, IN, USA) and set up for the index PCR with Nextera XT index primers (Illumina, San Diego, CA, United States). The indexed samples were purified using AMPure XP beads, quantified using a fragment analyzer (Agilent, Santa Clara, CA, USA), and equal quantities from each sample were pooled. The resulting pooled library was quantified using the Bioanalyzer 7500 DNA kit (Agilent) and sequenced using the v3-v4 chemistry $(2 \times 300$ bp paired-end reads).

\subsubsection{QPCR}

Quantitative PCR (QPCR) was used to validate the sequencing results for the following bacterial groups: Bifidobacterium spp., Lactobacillus spp., Enterobacteriaceae and total bacteria. For the QPCR, standard curves were prepared with pooled aliquots of caecal and colonic digesta DNA, as described previously [49]. Domain, genus and family specific primers are presented in Table 12. The selected bacterial groups were estimated based on gene copy number (GCN) in the digesta using QPCR on the 7500 Fast Real-Time PCR system (Applied Biosystems). QPCR was carried out in a final reaction 
volume of $20 \mu \mathrm{L}$ containing $3 \mu \mathrm{L}$ template DNA, $1 \mu \mathrm{L}$ of forward and reverse primers (100 pM), $10 \mu \mathrm{L}$ SYBR Green PCR master mix (Applied Biosystems) and $5 \mu \mathrm{L}$ nuclease-free water. The thermal cycling conditions involved an initial denaturation step at $95^{\circ} \mathrm{C}$ for $10 \mathrm{~min}$, followed by 40 cycles of $95^{\circ} \mathrm{C}$ for $15 \mathrm{~s}$ and $65^{\circ} \mathrm{C}$ for $1 \mathrm{~min}$. Dissociation curves confirmed the specificity of the final PCR products. All samples were prepared in duplicate, and the mean threshold cycle $(\mathrm{Ct})$ value was used for calculations. The estimates of GCN for selected bacteria were log-transformed and are presented as GCN per gram of digesta.

Table 12. Oligonucleotide sequences of forward and reverse primers used for QPCR of bacterial 16 s rRNA.

\begin{tabular}{cccc}
\hline Target Bacteria & $\begin{array}{c}\text { Forward Primer }\left(\mathbf{5}^{\prime}-\mathbf{3}^{\prime}\right) \\
\text { Reverse Primer }\left(\mathbf{5}^{\prime}-\mathbf{3}^{\prime}\right)\end{array}$ & Tm & Amplicon Size (bp) \\
\hline \multirow{2}{*}{ Total bacteria } & F: GTGCCAGCMGCCGCGGTAA & 64.2 & 291 \\
& R: GACTACCAGGGTATCTAAT & 52.4 & \multirow{2}{*}{385} \\
\hline \multirow{2}{*}{ Enterobacteriaceae } & F: ATGGCTGTCGTCAGCTCGT & 58.8 & \multirow{2}{*}{206} \\
\hline \multirow{2}{*}{ Lactobacillus spp. } & R: CCTACTTCTTTTGCAACCCACTC & 60.6 & \multirow{2}{*}{244} \\
\hline \multirow{2}{*}{ Bifidobacterium spp. } & RAGGCAGCAGTAGGGAATCTTC & 60.5 & 62.5 \\
\hline
\end{tabular}

$\mathrm{Tm}$, melting temperature; $\mathrm{bp}$, base pair.

\subsection{VFA}

Digesta from the caecum and colon was collected to determine VFA concentrations using gas-liquid chromatography according to the method described by Pierce et al. [50]. A $1 \mathrm{~g}$ sample was diluted with distilled water $(2.5 \times$ weight of sample) and centrifuged at $1400 \times g$ for $10 \mathrm{~min}$ (Sorvall GLC-2 B laboratory centrifuge, DuPont, Wilmington, DE, USA). One $\mathrm{mL}$ of the subsequent supernatant and $1 \mathrm{~mL}$ of internal standard ( $0.05 \% 3$-methyl- $n$-valeric acid in $0.15 \mathrm{M}$ oxalic acid dihydrate) were mixed with 3 $\mathrm{mL}$ of distilled water. The reaction mixture was centrifuged at $500 \times \mathrm{g}$ for $10 \mathrm{~min}$, and the supernatant was filtered through 0.45 PTFE (polytetrafluoroethylene) syringe filter into a chromatographic sample vial. An injection volume of $1 \mu \mathrm{L}$ was injected into a Varian $3800 \mathrm{GC}$ equipped with an EC ${ }^{\text {TM }} 1000$ Grace column $(15 \mathrm{~m} \times 0.53 \mathrm{~mm}$ I.D) with $1.20 \mu \mathrm{m}$ film thickness. The temperature programme set was $75-95^{\circ} \mathrm{C}$ increasing by $3{ }^{\circ} \mathrm{C} /$ minute, $95-200{ }^{\circ} \mathrm{C}$ increasing by $20^{\circ} \mathrm{C} /$ minute, which was held for 0.50 $\mathrm{min}$. The detector and injector temperature were 280 and $240^{\circ} \mathrm{C}$, respectively, while the total analysis time was $12.42 \mathrm{~min}$.

\subsection{Bioinformatic and Statistical Analyses}

The resulting sequences were analysed using the open source software package Quantitative Insights into Microbial Ecology (Qiime) [51]. Initially, sequencing primers were removed using the cutadapt function of Qiime. Paired-end reads were then joined with the multiple join paired-end reads function within Qiime using the default parameters. Using the split libraries function, the raw reads were initially demultiplexed, and reads were quality filtered using default QIIME parameters and sequences that contained ambiguous characters, non-exact barcode matches, sequence length $<225$ nucleotides and having a read-quality score of $<27$ were removed. OTUs were picked at 97\% sequence similarity using the uclust function within Qiime [51,52]. Singletons were removed, as only OTUs that were present at the level of at least two reads in more than one sample were retained. The resulting OTU representative sequences were assigned to different taxonomic levels (from phylum to species) using the GreenGenes database. Chimeras were identified and removed with the use of ChimeraSlayer [53,54]. The normalized OTU table combined with the phenotype metadata and phylogenetic tree comprised the data matrix. This matrix was then input into the 
phyloseq package within the R (http://www.r-project.org; version 3.5.0). The dynamics of richness and diversity in the piglet's microbiota were computed with the observed, the Simpson and the Shannon indices. The Simpson and Shannon indices of diversity account for both richness and evenness parameters. To estimate beta diversity measurements, which are a measure of separation of the phylogenetic structure of the OTU in one sample compared with all other samples, the data was normalised to make taxonomic feature counts comparable across samples. Several distance metrics were considered, in order to calculate the distance matrix of the different multidimensional reduction methods. These included weighted/unweighted UniFrac distance and non-phylogenetic distance metrics (i.e., Bray-Curtis, Jensen-Shannon divergence and Euclidian) using phyloseq in R $[55,56]$. Taxonomy and diversity plots were produced using graphics tailored for phylogenetic analysis using the R package ggplot2 [57]. Differential abundance testing was performed using the phyloseq to deseq2 function within R [56,58]. Results are presented using Benjamini-Hochberg (BH) adjusted $p$-values.

All other data were initially checked for normality using the univariate procedure of Statistical Analysis Software (SAS) 9.4 (SAS Institute, Cary, NC, USA). The performance data and FS data were analysed using repeated measures within the mixed procedure of SAS, and the model included fixed effects of treatment, time and their associated interactions. The initial weight was used as a covariate for the performance data. The data on intestinal morphology, microbial populations, gene expression and volatile fatty acids were analysed using the GLM procedure of SAS. The model assessed the effect of treatment, with the pig being the experimental unit. The probability level that denoted significance was $p<0.05$, while $p$-values between 0.05 and 0.1 are considered numerical tendencies. Data are presented as least-square means with their standard errors of the mean.

\section{Conclusions}

The improved faecal consistency observed in fucoidan-supplemented pigs was likely related to increased water absorption associated with the increased VFAs in the colon. Despite the reduced expression of genes involved in nutrient digestion and transport, this extract did not negatively impact growth performance or small intestinal morphology. Thus, fucoidan derived from A. nodosum at 250 ppm warrants further study for use as a dietary supplement to prevent post-weaning diarrhoea in more challenging conditions such as those observed on commercial farms. This fucoidan-rich extract also demonstrated effects on the gene expression of digestive enzymes, nutrient transporters and an increase in colonic propionate, effects which suggest it merits further investigation as a dietary supplement for the prevention or treatment of metabolic diseases.

Supplementary Materials: The following are available online at http://www.mdpi.com/1660-3397/17/12/680/s1, Supplementary document 1: Figure S1. The effect of fucoidan on alpha diversity measures; Tables S1-S4: The effect of fucoidan on gene expression in the small and large intestine. Supplementary Table S1: Effect of fucoidan on the relative abundance of bacteria in the caecum. Supplementary Table S2: Effect of fucoidan on the relative abundance of bacteria in the colon.

Author Contributions: Conceptualization, J.V.O. and T.S.; methodology, R.R.; formal analysis, R.R., S.V. and J.V.O.; investigation, R.R.; data curation, R.R., S.V., K.T. and G.R.; writing-original draft preparation, R.R.; writing-review and editing, R.R., J.V.O. and T.S.; funding acquisition, J.V.O. and T.S.

Funding: This research was funded by Science Foundation Ireland, grant number 14/IA/2548.

Acknowledgments: The authors acknowledge the contribution of the farm and laboratory staff in Lyons Research Farm and the School of Veterinary Medicine at University College Dublin.

Conflicts of Interest: The authors declare no conflict of interest.

\section{References}

1. Pluske, J.R. Feed- and feed additives-related aspects of gut health and development in weanling pigs. J. Anim. Sci. Biotechnol. 2013, 4, 1. [CrossRef] [PubMed]

2. Pluske, J.R.; Hampson, D.J.; Williams, I.H. Factors influencing the structure and function of the small intestine in the weaned pig: A review. Livest. Prod. Sci. 1997, 51, 215-236. [CrossRef] 
3. Lallès, J.; Boudry, G.; Favier, C.; Le Floc'Ha, N.; Luron, I.; Montagne, L.; Oswald, I.P.; Pie, S.; Piel, C.; Seve, B. Gut function and dysfunction in young pigs: Physiology. Anim. Res. 2004, 53, 301-316. [CrossRef]

4. Kim, J.C.; Hansen, C.F.; Mullan, B.P.; Pluske, J.R. Nutrition and pathology of weaner pigs: Nutritional strategies to support barrier function in the gastrointestinal tract. Anim. Feed Sci.Technol. 2012, 173, 3-16. [CrossRef]

5. European Parliament. Veterinary Medicines: Another Step in Fighting Antibiotic resistance. Available online: http://www.europarl.europa.eu/news/en/headlines/society/20181018STO16580/veterinary-medicinesfighting-antibiotic-resistance (accessed on 22 May 2019).

6. Holdt, S.L.; Kraan, S. Bioactive compounds in seaweed: Functional food applications and legislation. J. Appl. Phycol. 2011, 23, 543-597. [CrossRef]

7. Fitton, J.H. Therapies from Fucoidan; Multifunctional Marine Polymers. Mar. Drugs 2011, 9, 1731-1760. [CrossRef]

8. Catarino, M.D.; Silva, A.M.S.; Cardoso, S.M. Phycochemical Constituents and Biological Activities of Fucus spp. Mar. Drugs 2018, 16, 249. [CrossRef]

9. Walsh, A.M.; Sweeney, T.; O'Shea, C.J.; Doyle, D.N.; O’Doherty, J.V. Effect of dietary laminarin and fucoidan on selected microbiota, intestinal morphology and immune status of the newly weaned pig. Br. J. Nutr. 2013, 110, 1630-1638. [CrossRef]

10. Rajauria, G.; Draper, J.; McDonnell, M.; O'Doherty, J.V. Effect of dietary seaweed extracts, galactooligosaccharide and vitamin E supplementation on meat quality parameters in finisher pigs. Innov. Food Sci. Emerg. 2016, 37, 269-275. [CrossRef]

11. Sweeney, T.; O'Doherty, J.V. Marine macroalgal extracts to maintain gut homeostasis in the weaning piglet. Domest. Anim. Endocrinol. 2016, 56, S84-S89. [CrossRef]

12. Sweeney, T.; Dillon, S.; Fanning, J.; Egan, J.; O'Shea, C.J.; Figat, S.; Gutierrez, J.J.M.; Mannion, C.; Leonard, F.; O'Doherty, J.V. Evaluation of seaweed-derived polysaccharides on indices of gastrointestinal fermentation and selected populations of microbiota in newly weaned pigs challenged with Salmonella Typhimurium. Anim. Feed Sci. Technol. 2011, 165, 85-94. [CrossRef]

13. Lynch, M.B.; Sweeney, T.; Callan, J.J.; O'Sullivan, J.T.; O’Doherty, J.V. The effect of dietary Laminaria-derived laminarin and fucoidan on nutrient digestibility, nitrogen utilisation, intestinal microflora and volatile fatty acid concentration in pigs. J. Sci. Food Agric. 2010, 90, 430-437. [CrossRef] [PubMed]

14. Walsh, A.M.; Sweeney, T.; O'Shea, C.J.; Doyle, D.N.; O'Doherty, J.V. Effect of supplementing varying inclusion levels of laminarin and fucoidan on growth performance, digestibility of diet components, selected faecal microbial populations and volatile fatty acid concentrations in weaned pigs. Anim. Feed Sci. Technol. 2013, 183, 151-159. [CrossRef]

15. O'Doherty, J.V.; McDonnell, P.; Figat, S. The effect of dietary laminarin and fucoidan in the diet of the weanling piglet on performance and selected faecal microbial populations. Livestock Sci. 2010, 134, $208-210$. [CrossRef]

16. Gresse, R.; Chaucheyras-Durand, F.; Fleury, M.A.; Van de Wiele, T.; Forano, E.; Blanquet-Diot, S. Gut Microbiota Dysbiosis in Postweaning Piglets: Understanding the Keys to Health. Trends Microbiol. 2017, 25, 851-873. [CrossRef]

17. Nowland, T.L.; Plush, K.J.; Barton, M.; Kirkwood, R.N. Development and Function of the Intestinal Microbiome and Potential Implications for Pig Production. Animals 2019, 9, 76. [CrossRef]

18. Garcia-Vaquero, M.; Rajauria, G.; O’Doherty, J.V.; Sweeney, T. Polysaccharides from macroalgae: Recent advances, innovative technologies and challenges in extraction and purification. Food Res. Int. 2017, 99, 1011-1020. [CrossRef]

19. Mabeau, S.; Fleurence, J. Seaweed in Food-Products: Biochemical and Nutritional Aspects. Trends Food Sci. Technol. 1993, 4, 103-107. [CrossRef]

20. Kadam, S.U.; Tiwari, B.K.; O’Donnell, C.P. Application of Novel Extraction Technologies for Bioactives from Marine Algae. J. Agric. Food Chem. 2013, 61, 4467-4675. [CrossRef]

21. Gardiner, G.E.; Campbell, A.J.; O’Doherty, J.V.; Pierce, E.; Lynch, P.B.; Leonard, F.C.; Stanton, C.; Ross, R.P.; Lawlor, P.G. Effect of Ascophyllum nodosum extract on growth performance, digestibility, carcass characteristics and selected intestinal microflora populations of grower-finisher pigs. Anim. Feed Sci. Technol. 2008, 141, 259-273. [CrossRef] 
22. Cromwell, G.L. Why and how antibiotics are used in swine production. Anim. Biotechnol. 2002, 13, 7-27. [CrossRef] [PubMed]

23. Guevarra, R.B.; Hong, S.H.; Cho, J.H.; Kim, B.R.; Shin, J.; Lee, J.H.; Kang, B.N.; Kim, Y.H.; Wattanaphansak, S.; Isaacson, R.E.; et al. The dynamics of the piglet gut microbiome during the weaning transition in association with health and nutrition. J. Anim. Sci. Biotechnol. 2018, 9, 54. [CrossRef] [PubMed]

24. Kim, H.B.; Isaacson, R.E. The pig gut microbial diversity: Understanding the pig gut microbial ecology through the next generation high throughput sequencing. Vet. Microbiol. 2015, 177, 242-251. [CrossRef] [PubMed]

25. Flint, H.J.; Duncan, S.H.; Scott, K.P.; Louis, P. Links between diet, gut microbiota composition and gut metabolism. Proc. Nutr. Soc. 2015, 74, 13-22. [CrossRef]

26. Bergman, E.N. Energy contributions of volatile fatty acids from the gastrointestinal tract in various species. Physiol. Rev. 1990, 70, 567-590. [CrossRef]

27. Williams, B.A.; Verstegen, M.W.A.; Tamminga, S. Fermentation in the large intestine of single-stomached animals and its relationship to animal health. Nutr. Res. Rev. 2001, 14, 207-227. [CrossRef]

28. Jha, R.; Berrocoso, J.D. Review: Dietary fiber utilization and its effects on physiological functions and gut health of swine. Animal 2015, 9, 1441-1452. [CrossRef]

29. Yasutake, H.; Goda, T.; Takase, S. Dietary regulation of sucrase-isomaltase gene expression in rat jejunum. Biochim. Biophys. Acta 1995, 1243, 270-276. [CrossRef]

30. Kim, K.T.; Rioux, L.E.; Turgeon, S.L. Alpha-amylase and alpha-glucosidase inhibition is differentially modulated by fucoidan obtained from Fucus vesiculosus and Ascophyllum nodosum. Phytochemistry 2014, 98, 27-33. [CrossRef]

31. Kim, K.-T.; Rioux, L.-E.; Turgeon, S.L. Molecular weight and sulfate content modulate the inhibition of $\alpha$-amylase by fucoidan relevant for type 2 diabetes management. PharmaNutrition 2015, 3, 108-114. [CrossRef]

32. Roder, P.V.; Geillinger, K.E.; Zietek, T.S.; Thorens, B.; Koepsell, H.; Daniel, H. The role of SGLT1 and GLUT2 in intestinal glucose transport and sensing. PLOS ONE 2014, 9, e89977. [CrossRef] [PubMed]

33. Harada, N.; Inagaki, N. Role of sodium-glucose transporters in glucose uptake of the intestine and kidney. J. Diabetes Investig. 2012, 3, 352-353. [CrossRef] [PubMed]

34. Zhang, Y.; Viennois, E.; Zhang, M.; Xiao, B.; Han, M.K.; Walter, L.; Garg, P.; Merlin, D. PepT1 Expression Helps Maintain Intestinal Homeostasis by Mediating the Differential Expression of miRNAs along the Crypt-Villus Axis. Sci. Rep. 2016, 6, 27119. [CrossRef] [PubMed]

35. Gajda, A.M.; Storch, J. Enterocyte fatty acid-binding proteins (FABPs): Different functions of liver and intestinal FABPs in the intestine. Prostaglandins Leukot. Essent. Fatty Acids 2015, 93, 9-16. [CrossRef] [PubMed]

36. Jiménez-Escrig, A.; Sánchez-Muniz, F.J. Dietary fibre from edible seaweeds: Chemical structure, physicochemical properties and effects on cholesterol metabolism. Nut. Res. 2000, 20, 585-598. [CrossRef]

37. Hoebler, C.; Guillon, F.; Darcy-Vrillon, B.; Vaugelade, P.; Lahaye, M.; Worthington, E.; Duee, P.H.; Barry, J.L. Supplementation of pig diet with algal fibre changes the chemical and physicochemical characteristics of digesta. J. Sci. Food Agric. 2000, 80, 1357-1364. [CrossRef]

38. Dyer, J.; Salmon, K.S.; Zibrik, L.; Shirazi-Beechey, S.P. Expression of sweet taste receptors of the T1R family in the intestinal tract and enteroendocrine cells. Biochem. Soc. Trans. 2005, 33, 302-305. [CrossRef]

39. Sciascia, Q.; Das, G.; Metges, C.C. The pig as a model for humans: Effects of nutritional factors on intestinal function and health. J. Anim. Sci. 2016, 94, 441-452. [CrossRef]

40. Wang, Y.; Xing, M.C.; Cao, Q.; Ji, A.G.; Liang, H.; Song, S.L. Biological Activities of Fucoidan and the Factors Mediating Its Therapeutic Effects: A Review of Recent Studies. Mar. Drugs 2019, 17, 183. [CrossRef]

41. Kim, M.J.; Chang, U.J.; Lee, J.S. Inhibitory effects of Fucoidan in 3T3-L1 adipocyte differentiation. Mar. Biotechnol. 2009, 11, 557-562. [CrossRef]

42. Chambers, E.S.; Viardot, A.; Psichas, A.; Morrison, D.J.; Murphy, K.G.; Zac-Varghese, S.E.; MacDougall, K.; Preston, T.; Tedford, C.; Finlayson, G.S.; et al. Effects of targeted delivery of propionate to the human colon on appetite regulation, body weight maintenance and adiposity in overweight adults. Gut 2015, 64, 1744-1754. [CrossRef] [PubMed]

43. Ganesan, A.R.T.; Tiwari, U.; Rajuaria, G. Seaweed nutraceuticals and their therapeutic role in disease prevention. Food Sci. Hum. Wellness 2019, 8, 252-263. [CrossRef] 
44. NRC. Proteins and Amino Acids. In Nutrient Requirements of Swine, 11th ed.; National Academic Press: Washington, DC, USA, 2012; pp. 15-38.

45. Sauvant, D.; Perez, J.M.; Tran, G. Tables of composition and nutritional value. In Table of Composition and Nutritional Value of Feed Materials. Pigs, Poultry, Cattle, Sheep, Goats, Rabbits, Horses, Fish; Wageningen Academic Publishers: Wageningen, The Netherlands, 2004; pp. 77-302.

46. Van Soest, P.V.; Robertson, J.B.; Lewis, B.A. Methods for dietary fiber, neutral detergent fiber, and nonstarch polysaccharides in relation to animal nutrition. J. Dairy Sci. 1991, 74, 3583-3597. [CrossRef]

47. Geiss, G.K.; Bumgarner, R.E.; Birditt, B.; Dahl, T.; Dowidar, N.; Dunaway, D.L.; Fell, H.P.; Ferree, S.; George, R.D.; Grogan, T.; et al. Direct multiplexed measurement of gene expression with color-coded probe pairs. Nat. Biotechnol. 2008, 26, 317. [CrossRef]

48. Vigors, S.; JV, O.D.; Ryan, M.; Sweeney, T. Analysis of the basal colonic innate immune response of pigs divergent in feed efficiency and following an ex vivo lipopolysaccharide challenge. Physiol. Genomics 2019, 51, 443-448. [CrossRef]

49. O'Shea, C.J.; Sweeney, T.; Bahar, B.; Ryan, M.T.; Thornton, K.; O’Doherty, J.V. Indices of gastrointestinal fermentation and manure emissions of growing-finishing pigs as influenced through singular or combined consumption of Lactobacillus plantarum and inulin. J. Anim. Sci. 2012, 90, 3848-3857. [CrossRef]

50. Pierce, K.M.; Sweeney, T.; Callan, J.J.; Byrne, C.; McCarthy, P.; O’Doherty, J.V. The effect of inclusion of a high lactose supplement in finishing diets on nutrient digestibility, nitrogen excretion, volatile fatty acid concentrations and ammonia emission from boars. Anim. Feed Sci. Technol. 2006, 125, 45-60. [CrossRef]

51. Caporaso, J.G.; Kuczynski, J.; Stombaugh, J.; Bittinger, K.; Bushman, F.D.; Costello, E.K.; Fierer, N.; Peña, A.G.; Goodrich, J.K.; Gordon, J.I.; et al. QIIME allows analysis of high-throughput community sequencing data. Nat. Methods 2010, 7, 335-336. [CrossRef]

52. Rideout, J.R.; He, Y.; Navas-Molina, J.A.; Walters, W.A.; Ursell, L.K.; Gibbons, S.M.; Chase, J.; McDonald, D.; Gonzalez, A.; Robbins-Pianka, A.; et al. Subsampled open-reference clustering creates consistent, comprehensive OTU definitions and scales to billions of sequences. PeerJ 2014, 2, e545. [CrossRef]

53. DeSantis, T.Z.; Hugenholtz, P.; Larsen, N.; Rojas, M.; Brodie, E.L.; Keller, K.; Huber, T.; Dalevi, D.; Hu, P.; Andersen, G.L. Greengenes, a chimera-checked $16 \mathrm{~S}$ rRNA gene database and workbench compatible with ARB. Appl. Environ. Microb. 2006, 72, 5069-5072. [CrossRef]

54. Haas, B.J.; Gevers, D.; Earl, A.M.; Feldgarden, M.; Ward, D.V.; Giannoukos, G.; Ciulla, D.; Tabbaa, D.; Highlander, S.K.; Sodergren, E.; et al. Chimeric $16 \mathrm{~S}$ rRNA sequence formation and detection in Sanger and 454-pyrosequenced PCR amplicons. Genome. Res. 2011, 21, 494-504. [CrossRef] [PubMed]

55. Hamady, M.; Lozupone, C.; Knight, R. Fast UniFrac: Facilitating high-throughput phylogenetic analyses of microbial communities including analysis of pyrosequencing and PhyloChip data. ISME J. 2010, 4, 17-27. [CrossRef]

56. McMurdie, P.J.; Holmes, S. phyloseq: An R Package for Reproducible Interactive Analysis and Graphics of Microbiome Census Data. PLoS ONE 2013, 8, e61217. [CrossRef] [PubMed]

57. Wickham, H. ggplot2: Elegant Graphics for Data Analysis; Springer: New York, NY, USA, 2009.

58. Love, M.I.; Huber, W.; Anders, S. Moderated estimation of fold change and dispersion for RNA-seq data with DESeq2. Genome. Biol. 2014, 15, 550. [CrossRef] [PubMed]

(C) 2019 by the authors. Licensee MDPI, Basel, Switzerland. This article is an open access article distributed under the terms and conditions of the Creative Commons Attribution (CC BY) license (http://creativecommons.org/licenses/by/4.0/). 